MATEC Web of Conferences 3, 01017 (2013)

DOI: $10.1051 /$ matecconf/20130301017

(C) Owned by the authors, published by EDP Sciences, 2013

\title{
Prevention of the scaling in water distribution systems
}

\author{
M. Ben Amor, and M. Tlili
}

Laboratoire de Traitement des Eaux Naturelles, Centre de Recherches et Technologies des Eaux Water (CERTE), Technopole de Borj Cédria, 8020 Soliman, Tunisie

\section{Introduction}

Tunisian waters have a relatively high mineralization. Thus, $30 \%$ of the surface water and $80 \%$ of the groundwater have hardness greater than $30^{\circ} \mathrm{F}$. Therefore, the problem of scaling is acute in the industrial and agricultural sectors $[1,2]$. Operating systems and distribution of drinking water have not escaped this problem whose manifestations can be dramatic in some cases [3].

The work developed on scaling distribution conduit drinking water [4-7] show that the most affected circuits are fed by groundwater. It has been shown that the origin of this problem is an imbalance in the system after a calco-carbon intensive degassing of dissolved $\mathrm{CO}_{2}$. This parameter is often neglected over the mineralogical composition of water by farmers.

\section{Description of calco-carbonic system}

Among the various components of natural water, some are likely to react with each other in a system known as the calco-carbonic system " $\mathrm{CO}_{2}-\mathrm{H}_{2} \mathrm{O}-\mathrm{CaCO}_{3}$ " [8]. This three-phase system consists of a gas phase $\left(\mathrm{CO}_{2}\right)$, a liquid phase and a solid phase $\left(\mathrm{CaCO}_{3}\right)$. The exchange of $\mathrm{CO}_{2}$ between the liquid phase and the gas phase can be the main engine of scaling. The study of this system requires knowledge of all the balances that are established at the interfaces and in the liquid phase. $\Omega$ is defined as the supersaturation ratio of the product ion activity $\left(\mathrm{Ca}^{2+}\right)$ $\left(\mathrm{CO}_{3}{ }^{2-}\right)$ and the solubility product of calcium carbonate. This coefficient expresses the difference between the thermodynamic equilibrium of calcium carbonate and the concentration.

Precipitation of calcium carbonate is in tanks, pipes and water meters, whatever the nature of the materials. The following photos illustrate this phenomenon. The equation for the precipitation reaction of the calcium carbonate is represented as follow:

$$
\mathrm{Ca}^{2+}+2 \mathrm{HCO}_{3}^{-} \leftrightarrows \mathrm{CaCO}_{3(s d)}+\mathrm{CO}_{2(g a z)}+\mathrm{H}_{2} \mathrm{O}
$$

This equation is the result of two successive reactions:

$\mathrm{HCO}_{3}^{-}+\mathrm{H}_{3} \mathrm{O}^{+} \rightarrow \mathrm{CO}_{2}+2 \mathrm{H}_{2} \mathrm{O}$

$\mathrm{HCO}_{3}^{-}+\mathrm{Ca}^{2+}+\mathrm{H}_{2} \mathrm{O} \rightarrow \mathrm{CaCO}_{3}+\mathrm{H}_{3} \mathrm{O}^{+}$
The first reaction is the release of $\mathrm{CO}_{2}$ which is accompanied by a consumption of $\mathrm{H}_{3} \mathrm{O}^{+}$, where the increase the $\mathrm{pH}$. The second reaction is the precipitation of carbonate that is done with decreasing $\mathrm{pH}$. This degassing causes an increase in the $\mathrm{pH}$ and consequently increases the saturation until the onset of precipitation. Therefore, monitoring the change of $\mathrm{pH}$ values can detect this phenomenon and control it.

\section{Study of a real calcified circuit}

\subsection{Circuit diagnosis}

The diagnosis of calcified circuit shows that the causes of scaling are many and varied. But in the most cases, the release of dissolved $\mathrm{CO}_{2}$ causes the precipitation of $\mathrm{CaCO}_{3}$. The contact with air causes a material exchange that occurs between the water and the atmosphere, as carbon dioxide content is lower in the air $\left(\mathrm{pCO}_{2}=3.10^{-4}\right.$ $\mathrm{atm})$ than that of water $\left(\mathrm{pCO}_{2} \sim 10^{-1} \mathrm{~atm}\right)$ at the output of the drill.

In drinkable water circuits, degassing takes place in tarpaulins water tanks and wind loads. We present the diagnosis of a distribution of drinking water for a length of about $12 \mathrm{~km}$ that contains several glances of venting.

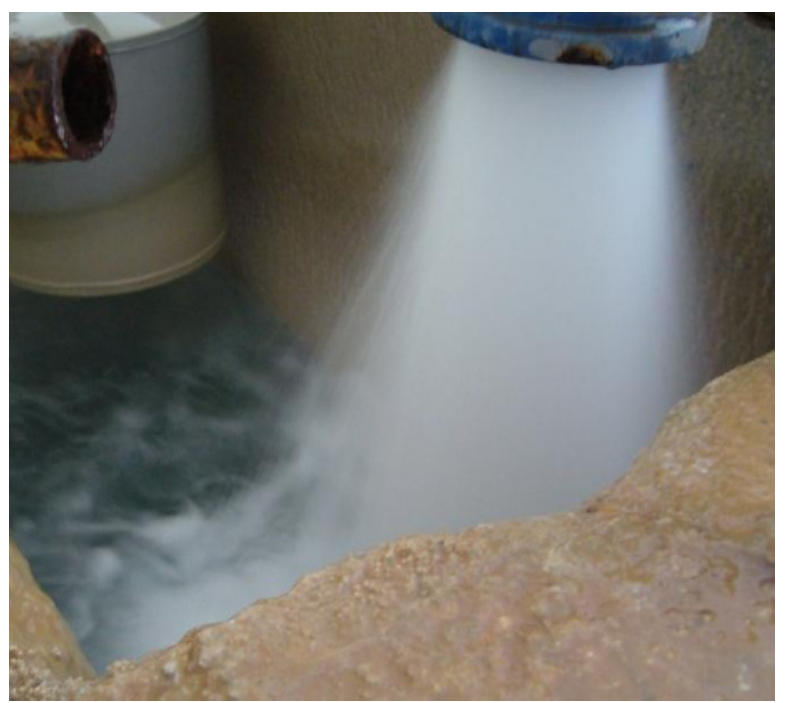

Photo 1. Photo of circuit breeze load of drinking water. 
$\mathrm{pH}$ measurements along the circuit (Figure 1) shows that the water comes out of the borehole at a $\mathrm{pH}$ equal to 7.48 and increases to 8.02, then it decreases.

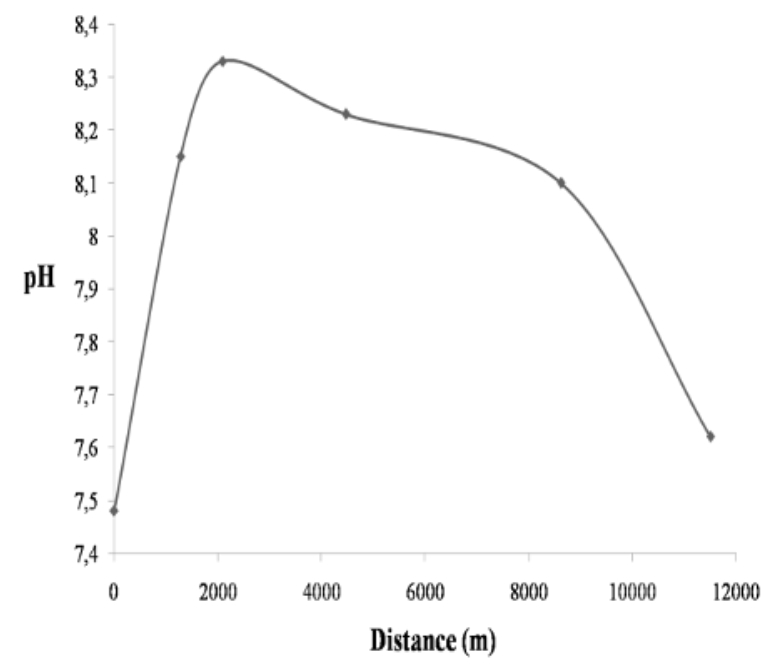

Figure 1. $\mathrm{pH}$ of the water as a function of the distance.

The examination of the circuit also shows that the precipitation of calcium carbonate engages from a distance of approximately 2000 meters where supersaturation is at its maximum. (Figure 2).

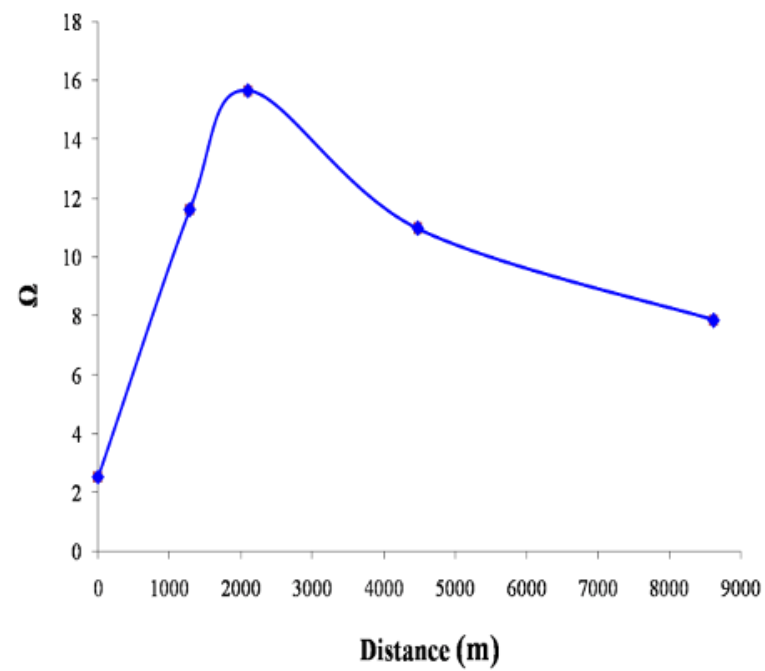

Figure 2. The supersaturation of the water as a function of the distance.

\subsection{Reduction of $\mathrm{CO}_{2}$ emission}

To overcome this situation we need to reduce the release of $\mathrm{CO}_{2}$ in the various circuits, particularly tank breezes loads and water tanks. To limit their lease of $\mathrm{CO}_{2}$, we propose two major interventions:

-The first is to drown all water in let sat tarpaulins

and glances of venting (Photos 3). - The second in cover in gall these circuits in order to keep the $\mathrm{CO}_{2}$ confined.

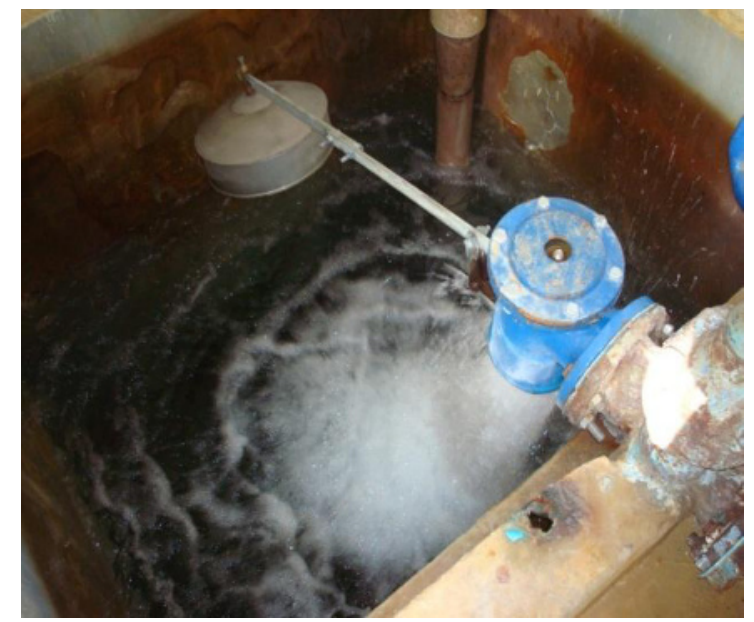

Photo 2. Photo of potable water tank and water charge breeze before intervention.

After the first operation we observe a decrease in the $\mathrm{pH}$ of the water throughout the circuit. This decrease is also greater after covering tarpaulins and glances of venting.

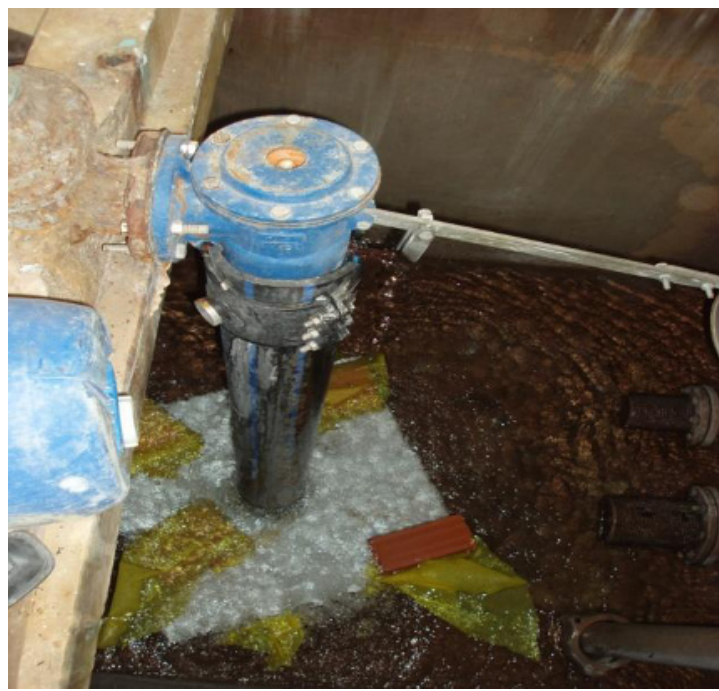

Photo 3. Photo of potable water tank and water glances of venting after intervention.

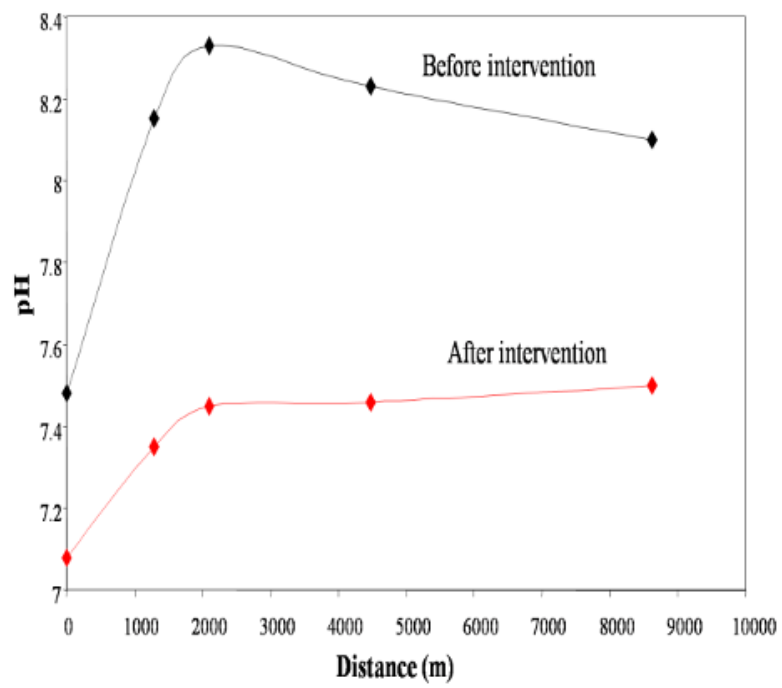

Figure 3. pH according to the distance before and after intervention. 


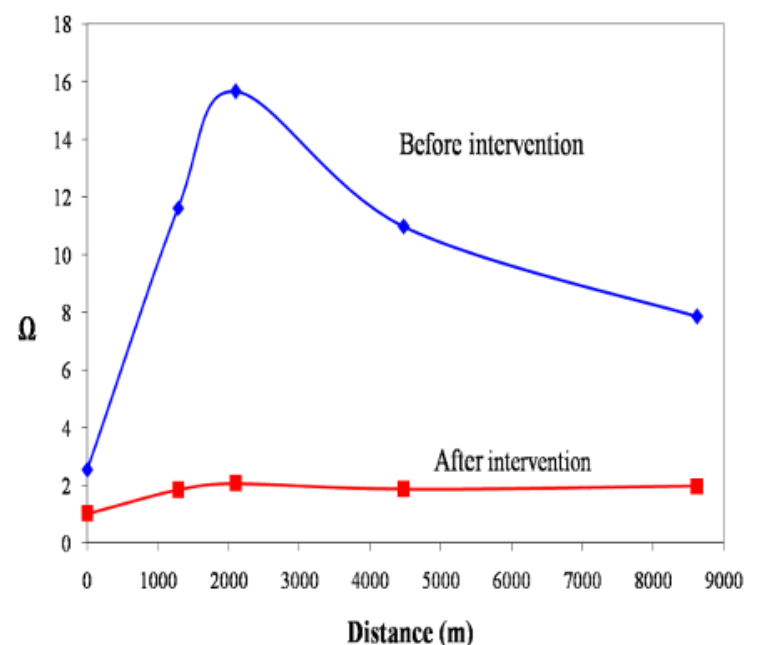

Figure 4. Saturation function of the distance before and after intervention.

This figure clearly shows that after the limited air/water contact, the $\mathrm{pH}$ stabilized at values well below the $\mathrm{pH}$ of precipitation.

This result is confirmed by the values of the supersaturation of calcium carbonate in water. After intervention, the saturation is maintained throughout the circuit.

\section{Conclusion}

This study shows that the control of $\mathrm{CO}_{2}$ can limit the scaling of distribution channels. This method is easy to implement and does not use any chemicals compound. So it is an environmentally friendly way.

\section{Acknowledgment}

We thank the management of the exploitation of northern SONEDE (Tunisia) for his work and all those who contributed to the completion of this study.

\section{References}

1. K. Walha, M. Ben Amor, R. Rosset, Journal de la Société Chimique de Tunisie (1997)

2. A.S. Manzola, Thèse de Doctorat, Faculté des sciences de Tunis, (2003)

3. M. Nefzi, Thèse de Doctorat, Faculté des sciences de Tunis, (2004)

4. A. Ghorbel, M.M. Tlili, K. Walha, M. Ben Amor, R. Rosset, Cahiers de l'Association Scientifique Européenne pour l'Eau et la santé 631 (2002)

5. M. Ben Amor et al. Rapport interne CERTE / SONEDE (2009)

6. N. Gache, Thèse de Doctorat. Université Montpellier II, (1998)

7. M.M. Tlili, Thèse de Doctorat. Université Paris VI. (2002)

8. M.M. Tlili, M. Ben Amor, C. Gabrielli, S. Joiret, G. Maurin, European Journal of Water Quality 3789 (2006) 